\title{
Depth gradients in diversity, distribution and habitat specialisation in coral reef fishes: implications for the depth-refuge hypothesis
}

\author{
M. W. Jankowski ${ }^{1,2, *}$, N. A. J. Graham ${ }^{2}$, G. P. Jones ${ }^{1,2}$ \\ ${ }^{1}$ College of Marine and Environmental Sciences, James Cook University, Townsville, Queensland 4811, Australia \\ ${ }^{2}$ ARC Centre of Excellence for Coral Reef Studies, James Cook University, Townsville, Queensland 4811, Australia
}

\begin{abstract}
Studies assessing the structure of coral reef fish assemblages have focused on shallow reefs and the importance of coral cover. However, the ecology of reef fish communities varies with depth, although trends in diversity, community structure and reliance on corals have seldom been described. Deeper reef habitats may provide refuge from shallow water disturbances, depending on the depth distributions of species and patterns of habitat specialisation with depth. We examined fish communities down to the bottoms of reefs at $20 \mathrm{~m}$. Communities comprised species with preferences for shallow water and others with broader depth ranges, which were more abundant at greater depths. Diversity exhibited linear declines with depth. Species that were common around the mid-point of the depth gradient had the greatest depth ranges, whereas depth ranges were more restricted at the shallow and deep extremes. Niche breadth decreased with increasing mean depth of occurrence, suggesting that deeper species were more specialised. Unexpectedly, there was a higher association with branching corals in the deepest strata, suggesting a greater reliance on coral habitat at the patchy reef edge. Clearly, there are dramatic changes in the ecology of reef fishes and their habitat between 0 and $20 \mathrm{~m}$, and a variety of physical and biological factors that are likely to be important. Although coral-associated species found deeper may occupy a refuge from shallow water disturbances, the narrow distributions of species at deeper depths and the high reliance on corals are unlikely to contribute to long-term resilience in relation to widespread reef degradation.
\end{abstract}

KEY WORDS: Reef fish ecology · Depth gradients · Depth-refuge hypothesis - Depth ranges · Niche breadth $\cdot$ Habitat use $\cdot$ Diversity

\section{INTRODUCTION}

One of the major goals of ecology is to try to explain patterns in distribution, diversity, species composition and niche breadth along environmental gradients (Krebs 2006). Species typically exhibit limited distributions and changes in abundance along environmental gradients such as altitude, latitude and depth (Hawkins 1999, La Peyre et al. 2001, Mark et al. 2001). The optimum position along these gradients may be a response to a number of intersecting physical gradients. For example, on mountains, spe- cies distributions may vary in response to altitude, slope and substrate type (Kappelle et al. 1995, Xu et al. 2011). Upper and lower limits of species distribution may be controlled by different factors, with environmental harshness often important at one extreme and biological interaction among species at the other (Connell 1961). Community-level metrics such as diversity also show distinct patterns along environmental gradients. For example, a decrease in diversity and species richness with increasing altitude has been found in communities of plants and insects such as butterflies (Kappelle et al. 1995, Leingärtner et al. 
2014). Diversity may not always be highest at one extreme of the environmental gradient, but may peak at a mid-point along the gradient where conditions are favourable for a larger number of species (Nogués-Bravo et al. 2008). Measures of specialisation such as niche breadth can also show changes along environmental gradients, with populations of species at the limits of their range usually having narrower niche breadths (Clavel et al. 2011, Silc et al. 2014). A full description of the key ecological patterns that vary along gradients is necessary to generate hypotheses about the critical factors involved and to understand how environmental changes may affect species.

Most studies on the distribution, abundance, diversity and community structure of coral reef fishes have focused on horizontal gradients such as exposure (McGehee 1994, Green 1996), reef zone (Green 1996, Lecchini et al. 2003, Arias-González et al. 2006) and spatial patterns in habitat structure (Friedlander \& Parrish 1998, Gratwicke \& Speight 2005, Garpe et al. 2006, Graham et al. 2006, Wilson et al. 2006, Bonin et al. 2011). These studies often highlight patterns of diversity and specialisation associated with branching coral cover and topographic complexity (Chabanet et al. 1997, Brokovich et al. 2008, Graham \& Nash 2013). However, the strongest physical and biological gradients on coral reefs are likely to be associated with depth gradients, where substantial trends in the physical and biotic environment can occur over a few metres (Brokovich et al. 2008, González-Sanson et al. 2009). Some changes in communities of fish have been found with increasing depth and the associated decline in coral cover (Brokovich et al. 2008). Not only can the abundance of individual species change with depth, but also familial composition of the community. For example, in the Red Sea, shallow waters tend to be dominated by damselfishes and gobies, whereas wrasses and groupers become more dominant at deeper depths (Brokovich et al. 2008). Differences in abundance can be observed between species of the same family and even the same genus, with examples known from pomacentrids (Bay et al. 2001), pomacanthids (Eagle et al. 2001), balistids (Bean et al. 2002), serranids (Donaldson 2002) and acanthurids and scarids (Hernandez-Landa et al. 2015). In all of these examples, species have been found to have different depth distributions, with some species or genera showing a preference for particular depths. Despite studies often showing changes in fish communities between different reef profiles or zones (e.g. reef flats, crests and slopes) which would include an aspect of depth (Green 1996,
Lecchini et al. 2003, Arias-González et al. 2006), these typical reef zones or profiles are defined in relation to several factors, including depth, exposure and reef profile (Jankowski et al. 2015). Therefore, in general, systematic changes to species abundance, depth ranges and niche breadth, specifically along depth gradients, have seldom been investigated.

Given that one of the key factors affecting the distribution and abundance of coral reef fishes is the structure of the underlying habitat, it is important to understand how habitat structure changes with depth and how fish reliance on particular habitats also changes. Coral cover has been implicated as an important determinant of depth distributions, with many coral-associated species restricted to shallow water (Bell \& Galzin 1984, Chabanet et al. 1997, Srinivasan 2003, Brokovich et al. 2006). However, experimental manipulation of habitat availability at different depths has shown that it may only make a partial contribution to explaining depth distributions (Srinivasan 2003). Depth gradients are associated with numerous, co-varying physical changes, including light attenuation, declining wave-induced disturbance, temperature and so on (Fulton \& Bellwood 2005, Fulton et al. 2005, Brokovich et al. 2008, Irisson et al. 2010). Larval supply has also been shown to be influenced by depth, with the distribution of fish larvae in the water column being structured by depth (Leis 1986, 1991, Irrison et al. 2010). This structuring coupled with larval habitat choice can play a role in the distributions of reef fish (Gutierrez 1998). Biological interactions such as competition may also affect fish distribution and the depths at which fish prefer to live (Bay et al. 2001, Bean et al. 2002). Changes in habitat availability and habitat use with depth may well result in different levels of specialisation at different depths. It is thought that shallow water species tend to be more specialised in their depth range (e.g. Bean et al. 2002), with smaller depth ranges in shallow water associated with more substantial changes in physical conditions. It has also been hypothesised that shallow water species will be more specialised on substratum types (Bean et al. 2002). Many coral reef fish are associated with live corals and have been found to be restricted to shallow habitats (Bell \& Galzin 1984, Chabanet et al. 1997, Srinivasan 2003, Coker et al. 2014). Deeper habitat can be more heterogeneous and therefore deeper species may be more generalist (Bean et al. 2002, Brokovich et al. 2008). The ability to exploit a wider range of habitats can potentially allow a fish to live at a wider range of depths. If deeper species tend to be generalists, then reliance on coral may decrease with increasing depth 
as coral cover and diversity also decline. However, as few studies have focused on these patterns, generalisations about trends in ecological specialisation with depth have not emerged.

Coral reefs are subject to both natural and an increasing array of anthropogenic disturbances. Many of these impacts more heavily affect shallow reefs (Bongaerts et al. 2010, Kahng et al. 2010, Bridge et al. 2013). Reduced effects from disturbances such as tropical cyclones, thermal bleaching, fishing, pollution and run-off have been recorded from depths $>10 \mathrm{~m}$, although these reduced effects are more commonly seen at depths $>25 \mathrm{~m}$ (Bak et al. 2005, Slattery et al. 2011, Bridge et al. 2013). This may afford some species a depth refuge, whereby species with wider depth distributions can survive impacts in shallow waters because individuals living at greater depths can act as a source of juveniles or because individuals can move to greater depths to lessen or escape impacts (Kahng et al. 2010). This has been demonstrated for several species, and depth may well need to be considered in marine reserve design (Kahng et al. 2010, Goetze et al. 2011, Bridge et al. 2013). If shallow species are more specialised and have more specific habitat preference (i.e. coral dependency) then it is possible that they may have an increased extinction risk compared to deeper species. Species that are more generalist in their depth distribution and therefore have extended depth ranges would potentially be less at risk considering that part of the population would not be impacted by a given disturbance in shallower depths (Graham et al. 2011). However, general predictions about species responses to shallow water anthropogenic disturbance must be founded on basic descriptions of natural changes in ecological traits along depth gradients.

The aim of this study was to quantify trends in depth ranges, diversity, species composition, habitat use and specialisation in coral reef fishes along a depth gradient down to the bottom of mid-shelf reefs at around $20 \mathrm{~m}$ on the Great Barrier Reef, Australia. Both fish and coral communities were sampled along depth profiles to test the following specific hypotheses for reef fishes. (1) Most damselfishes and wrasses will have limited distributions over a $20 \mathrm{~m}$ depth range. (2) Taxonomic diversity and taxonomic distinctness will decline with depth. (3) Species composition will change with depth, with the greatest changes over shallow depth strata where the greatest changes to the physical environment occur. (4) Shallow species will have smaller depth ranges than deeper species. (5) Shallow species will be more specialised in their habitat use than deeper species, with a decline in the reliance on coral as a preferred habitat with increasing depth. The identification of common and interacting responses to these factors is a necessary step towards evaluating whether deeper reef habitat may be a refuge to impacts on coral reefs. If so, such findings will have important implications for the future management of coral reef ecosystems.

\section{MATERIALS AND METHODS}

\section{Study site and species}

This study was carried out on 5 mid-shelf reefs of the central Great Barrier Reef (GBR) (Wheeler, Davies, John Brewer, Trunk and Rib), with 6 replicate sites sampled once on each reef (Fig. 1). The reefs were surveyed over 2 trips; 3 reefs were surveyed October 2010 (Wheeler, Davies and John Brewer) and the other 2 in January 2011 (Trunk and Rib). These mid-shelf platform reefs exhibit reef flats exposed at low tide, with reef slopes ending in sand at approximately $20 \mathrm{~m}$ (Graham et al. 2014). The fact that these reefs ended at $20 \mathrm{~m}$ allowed us to survey fish over the entire depth range of these particular reefs. For this

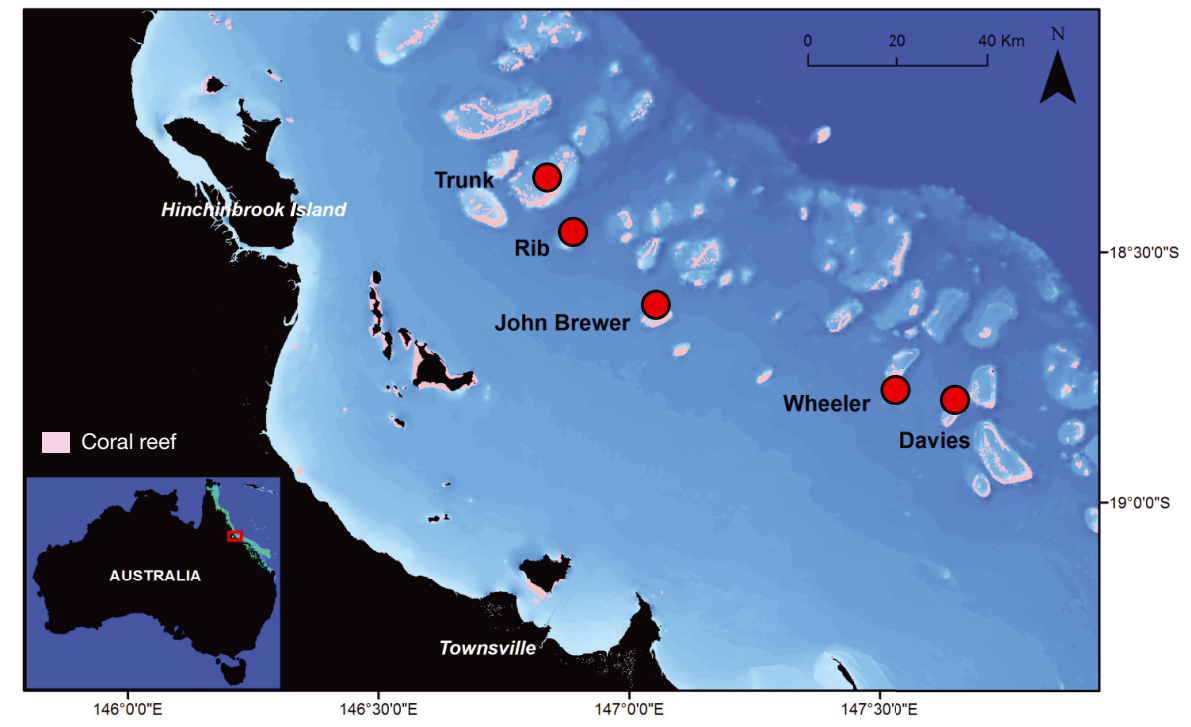

Fig. 1. The 5 mid-shelf Great Barrior Reef (GBR) reefs surveyed during this study and the surrounding region 
study we focused on habitat use and specialisation in species of the Pomacentridae (damselfishes) and Labridae (wrasses), 2 species-rich families that show a range in the degree of specialisation.

\section{Fish and benthic surveys}

The distribution, abundance and habitat use of pomacentrids and labrids was surveyed at different depths by carrying out a controlled and steady swim from a starting depth of $20 \mathrm{~m}$ at the bottom of the reef's profile up to the reef flat, typically $\sim 1 \mathrm{~m}$ depth at each of the 6 sites on each reef. Individual damselfishes and wrasses seen ahead within a $2 \mathrm{~m}$ belt were recorded. For each individual fish observed, the species, depth at which it was observed, and habitat type immediately below the fish was recorded. Fish seen in schools were counted, but only 5 individuals from each school observed were included to avoid a potential bias from very abundant species, whilst not losing any information from rarer species.

The changes of available benthic habitat were surveyed using photo-quadrats. The reef profile was divided into 4 arbitrary depth strata $(0-5,5-10$, 10-15 and 15-20 m). For each depth stratum, 20 to 30 photographs of the substratum were taken, with the camera $50 \mathrm{~cm}$ above the bottom, to keep the area photographed consistent and to keep the pictures clear enough to identify what was present. The first photograph for each depth stratum was taken haphazardly and then all other photographs for that depth stratum were taken at least 5 fin kicks away from the previous one. For each photograph the substratum at 5 random points was recorded. This was done using 9 benthic categories similar to those used by Wilson et al. (2008) (branching coral, plating coral, encrusting coral, massive coral, soft coral, algae/ dead coral, sand/rubble, consolidated coral pavement and 'other').

\section{Ecological metrics and data analyses}

When assessing the distribution patterns with depth we had to take into account unbalanced sampling caused by limitations in the amount of time that could be spent at depth. Due to safety limitations, more time was spent overall at shallow depths when carrying out surveys, which all lasted approximately 40 min. Distribution was, therefore, assessed by looking at the frequency of occurrence of species at the different depth strata studied. This was done by plot- ting presence/absence of the 6 most common species in each family across all sites and depths studied. To make sure results were not just by chance, we tested the data statistically using a chi-squared test of homogeneity.

Changes in fish diversity with depth were analysed using the measures of taxonomic diversity $(\Delta)$ and taxonomic distinctness $\left(\Delta^{*}\right)$. These measures of diversity consider relationships between species through taxonomic trees. Taxonomic diversity looks at the average path length between every pair of individuals in a sample, or, in other words, the expected path length between any 2 randomly chosen individuals from the sample. This measure can be considered as being related to standard diversity indices and is a generalisation of the Simpson diversity index incorporating an element of taxonomic relatedness (Clarke \& Warwick 1998). The taxonomic distinctness index was modified to remove some of the dependence on the species abundance distribution and therefore is more of a pure function of taxonomic relatedness. It is the expected path length between any 2 randomly chosen individuals from a sample, conditional on the samples being from different species (Warwick \& Clarke 1995, Clarke \& Warwick 1998). These taxonomic diversity metrics can take into account unbalanced sampling (Clarke \& Warwick 1998). As stated earlier, limitations in the amount of time that can be spent at depth meant that sampling was unbalanced, with more time spent at shallower depths, making these diversity measures appropriate. Diversity indices were calculated for $2 \mathrm{~m}$ depth-strata, based on the depth observations made for all individuals, in order to give a more continuous axis for plotting trends in diversity.

To assess changes in species composition with respect to depth and reefs, we used a non-metric multidimensional scaling plot (nMDS) (Primer-E V.6) using a Bray-Curtis resemblance matrix. Data were square root transformed to down-weight the effect of highly abundant species. Differences in depths and reefs were tested using a 2-way ANOSIM (Primer-E V.6). Changes in the depth distribution of species were analysed by calculating the total depth range for each species, which is the size of a species' depth range, and plotting this against the mean depth at which a species was observed. Due to the non-linear relationship in the data, we modelled it using a nonlinear model with a polynomial fit using the program R (V.3.1.0) (R Core Team 2014). Normality of residuals and homogeneity of variance were assessed using plots of residuals against fitted values and Q-Q plots, and the data fitted the assumptions. 
Specialisation was assessed by calculating niche breadth for each species. Niche breadth is a proportional similarity index, as used by Wilson et al. (2008), which takes into account the proportion of resources used by a population and the proportion of resources available to a population. The data used to calculate this were the habitat use data for each species as well as the habitat data. The index ranges between 0 and 1 , where lower values indicate a smaller niche breadth and therefore greater specialisation. We then assessed how niche breadth changed with depth by plotting it against the mean depth of occurrence for each species. This was also done using a non-linear model with a polynomial fit due to the non-linear pattern in the data using the program $\mathrm{R}$ (V.3.1.0) (R Core Team 2014). The data met the assumptions of normality of residuals and homogeneity of variance according to plots of residuals against fitted values and Q-Q normal plots. Habitat use was assessed for the communities of pomacentrids and labrids by combining the observations across all species and splitting them into the same 4 depth categories used when collecting data on habitat availability $(0-5,5-10,10-15$ and $15-20 \mathrm{~m})$. The percentage of fish observed and the percentage of habitat available for each habitat category were plotted. To further assess habitat selection, resource selection functions $\left(\hat{w}_{i}\right)$ were calculated following the formula:

$$
\hat{w}_{i}=u_{i+} /\left(\pi_{i} u_{++}\right)
$$

where $u_{i+}$ is the number of fish using habitat type $i_{1} \pi_{i}$ is the proportion of that habitat type available and $u_{++}$is the total number of fish using all habitat types (Manly et al. 1993). Confidence intervals (95\%) were calculated using the standard errors from the selectivity functions following methods outlined by Manly et al. (1993). These confidence intervals were then used to assess whether fish were using a particular habitat significantly more often based upon its availability. This was considered to be the case when both the selectivity index and associated confidence intervals were $>1$ (Manly et al. 1993).

\section{RESULTS}

\section{Distribution and abundance}

The 6 most common species within each family showed the range in the depth distributions observed, with similar patterns for both pomacentrids and labrids (Fig. 2a,b). There were species that showed a clear preference for shallow depths, with the damselfishes Stegastes apicalis and Pomacentrus bankanensis and the wrasses Thalassoma hardwicke, $T$. jansenii and $T$. ambycephalus all most common in the shallow depths $(0-5$ and 5-10 m) (Fig. 2a,b). For the damselfishes, $S$. apicalis and $P$. bankanensis were only observed at $0-5$ and 5-10 m. In contrast, $P$. moluccensis and $P$. brachialis were observed to occur at all depths but were observed to be more common at deeper depths (Fig. 2a). Among the labrids, both $T$. hardwicke and T. amblycephalus were only observed at $0-5$ and 5-10 m, while T. lunare and Halichoeres melanurus both showed patterns, in which, they occurred throughout the depth gradient but were most common at $10-15 \mathrm{~m}$ and least abundant at $0-5 \mathrm{~m}$. All these species showed a significant $(\alpha=0.01)$ effect of depth on their distribution (Table 1). Three species showed no significant effect of depth on their distribu-

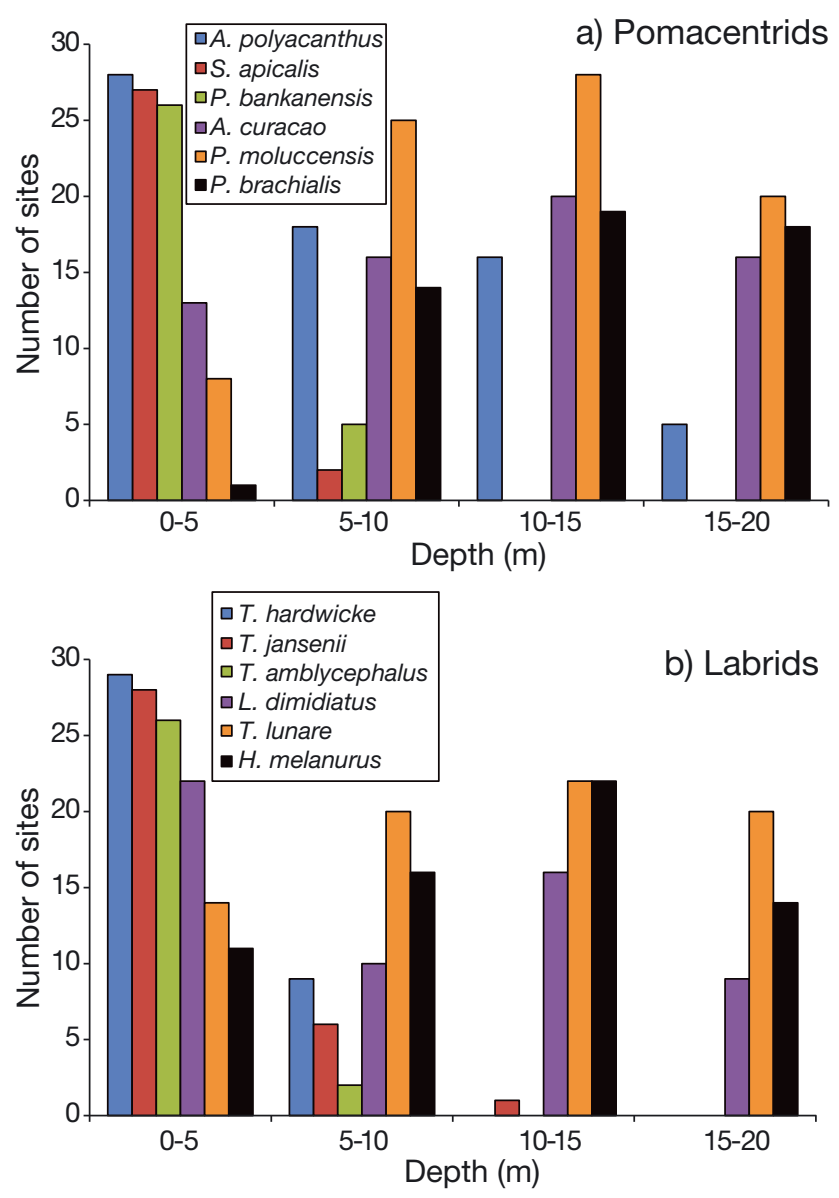

Fig. 2. Presence/absence data for the most abundant pomacentrid and labrid species observed in the study (see Table 1 for full taxonomic names). Shown are the number of sites in the study at which each species was observed across different depth strata along the gradient surveyed $(0-20 \mathrm{~m})$ at each site 
Table 1. Results of chi-squared tests of homogeneity on the depth distribution of the 6 most abundant species of pomacentrids and labrids observed during the surveys found in Fig. 1

\begin{tabular}{|lccr|}
\hline & df & Chi $^{2}$ & \multicolumn{1}{c|}{$\mathrm{p}$} \\
\hline Pomacentrids & & & \\
Acanthochromis polyacanthus & 3 & 5.037 & 0.169 \\
Stegastes apicalis & 3 & 49.366 & $<0.001$ \\
Pomacentrus bankanensis & 3 & 39.566 & $<0.001$ \\
Amblyglyphidodon curacao & 3 & 6.887 & 0.076 \\
Pomacentrus moluccensis & 3 & 19.797 & $<0.001$ \\
Pomacentrus brachialis & 3 & 28.609 & $<0.001$ \\
Labrids & & & \\
Thalassoma hardwicke & 3 & 22.611 & $<0.001$ \\
Thalassoma jansenii & 3 & 21.163 & $<0.001$ \\
Thalassoma amblycephalus & 3 & 27.831 & $<0.001$ \\
Labroides dimidiatus & 3 & 2.352 & 0.503 \\
Thalassoma lunare & 3 & 22.063 & $<0.001$ \\
Halichoeres melanurus & 3 & 19.438 & $<0.001$ \\
\hline
\end{tabular}

tions, these were the damselfishes Acanthochromis polyacanthus and Amblyglyphidodon curacao as well as the wrasse Labroides dimidiatus. Both A. polyacanthus and A. curacao were observed at all the depths surveyed, with $A$. polyacanthus observed more at shallow depths and A. curacao observed more at deeper depths (Fig. 2a).

\section{Species diversity and composition}

Taxonomic diversity and distinctness

There was a linear decline in taxonomic diversity with depth $\left(y=-0.6596 x+57.575, \mathrm{R}^{2}=0.770\right)$, indicating a decline in the taxonomic variety of species between 0 and $20 \mathrm{~m}$ (Fig. 3a). There was also a linear decline in taxonomic distinctness over the observed depth range $\left(y=-0.435 x+61.672, \mathrm{R}^{2}=0.585\right)$ (Fig. 3b). This indicates that in shallow water there is a greater variety of species that are more taxonomically distinct from one another. The fact that both taxonomic diversity and distinctness show similar trends suggests that the distribution of abundance observed is a consistent pattern across the depth gradient.

\section{Community composition}

The changes in fish community composition showed distinct patterns associated with both depth and reef locations (Fig. 4). There was a split in the data between communities at $0-5 \mathrm{~m}$ and communi- ties at the other depths surveyed. There was also a more gradual change between communities at 5-10 m through to communities at $15-20 \mathrm{~m}$. These patterns with depth were highly significant showing a strong effect (ANOSIM: $F=0.749, \mathrm{p}=0.003$ ). Multivariate dispersion between the communities in Fig. 4 increases with depth, showing that the species observed at deeper depths were more spatially different (Table 2). The differences among the 5 reefs were not as clear as depth. Wheeler Reef appeared to be the most distinct in terms of fish species present compared to the other reefs studied. The communities of fishes at Davies and Rib Reefs seemed to be quite similar to each other as did the communities at John Brewer and Trunk Reefs. Statistically these trends were marginally significant, suggesting the reef effect was not as strong as that of depth (ANOSIM: $F=0.242, \mathrm{p}=0.053$ ).
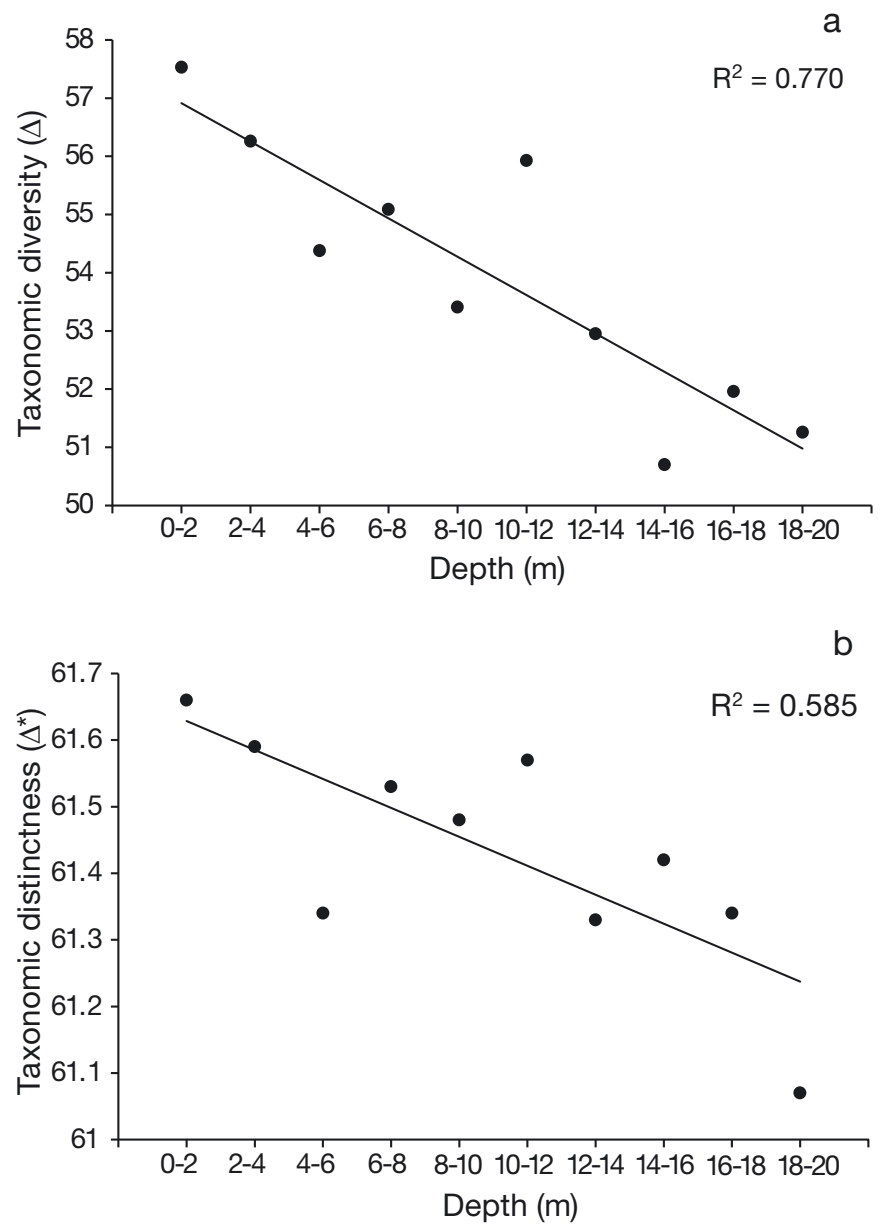

Fig. 3. Diversity data showing (a) taxonomic diversity $(\Delta)$ and (b) taxonomic distinctness $\left(\Delta^{*}\right)$ plotted against depth. Points represent the diversity measure for each $2 \mathrm{~m}$ depth stratum along the depth gradient surveyed $(0-20 \mathrm{~m})$ 


\section{Depth range and niche breadth}

There was an unexpected polynomial relationship between the total depth range of a species and the mean depth at which it occurred $\left(y=-0.2033 x^{2}+\right.$ $3.7397 x+1.5537, \mathrm{R}^{2}=0.5145$; ANOVA: $F=34.975$, $\mathrm{p}<0.001, \mathrm{df}=66$ ) (Fig. 5a, Table 3). The species that exhibited the greatest depth ranges were those whose depth range was centred on intermediate depths of 6-12 m. There were no species with narrow depth distributions at these intermediate depths. Species that primarily live at shallow depths had smaller, more restricted total depth ranges, as did those primarily found at $16-20 \mathrm{~m}$ at the deepest edge of the reef.

Contrary to expectations, niche breadth (specialisation) showed a negative trend in relation to mean depth of occurrence $\left(y=-0.0026 x^{2}+0.0213 x+\right.$ 0.6111, $\mathrm{R}^{2}=0.3509$; ANOVA: $F=15.138, \mathrm{p}<0.001$, $\mathrm{df}=56$ ) (Fig. 5b). Deeper species observed in this study exhibited a narrower, more specialised niche breadth than shallow species. Species with the shallowest mean depth and the greatest niche breadth were mobile planktivorous and benthic invertebrate feeding species, such as Abudefduf whitleyi and Anampses geographicus. Species with the deepest mean depth and smallest niche breadth included site-attached coral or sand/rubble species such as Dascyllus reticulatus and Chrysiptera rollandi associated with the edge of the reef. Very mobile omnivorous and carnivorous species, such as Thalassoma lunare, had niche breadths that were intermediate.

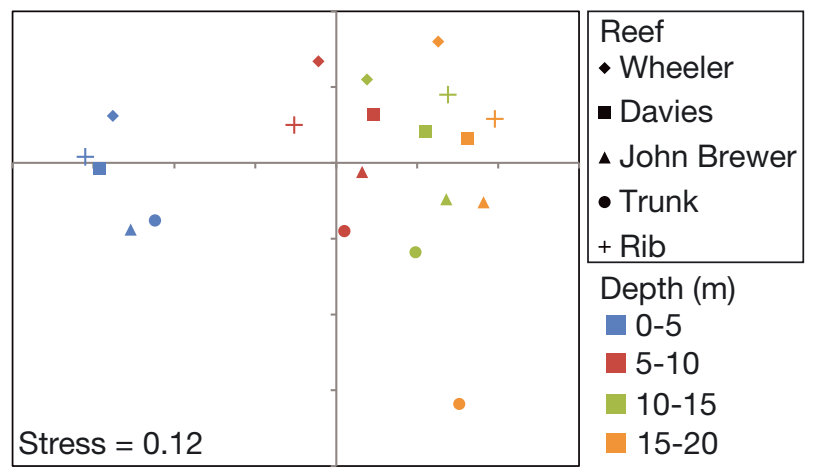

Fig. 4. Non-metric multidimensional scaling (nMDS) plot showing the similarities of fish communities observed at different depths for the 5 reefs surveyed during the study. Fish abundance data were categorised into 4 different depth strata $(0-5,5-10,10-15$ and $15-20 \mathrm{~m})$ for each reef. An ANOSIM was carried out on the data to test the significance of the groupings in the nMDS plot with depth (ANOSIM: $F=$ $0.749, \mathrm{p}=0.003$ ) and reef (ANOSIM: $F=0.242, \mathrm{p}=0.053$ ), both showing significant results
Table 2. Multivariate dispersion of communities at each depth stratum surveyed

\begin{tabular}{|lc|}
\hline Depth $(\mathrm{m})$ & Dispersion (MVDISP) \\
\hline $0-5$ & 0.332 \\
$5-10$ & 1.005 \\
$10-15$ & 1.195 \\
$15-20$ & 1.468 \\
\hline
\end{tabular}

However, overall there was a great deal of variation in niche breadths, particularly among species at shallow and intermediate depths.

\section{Reliance on coral}

The hypothesis that the dependence on coral would decline with increasing depth was not supported by the study (Fig. 6a). In fact the data show the opposite pattern, with deeper fish species having a stronger association with branching coral compared with shallow ones. The main differences in habitat use between shallow and deep fish were that a higher percentage of shallow fish used plating coral, algae/dead coral, consolidated pavement and massive coral, whereas a higher percentage of deep fish used branching coral, soft coral and sand/rubble (Fig. 6a). Manly selectivity indices showed that shallow species tended to select for plating coral, sand/rubble and soft coral, whereas deep species selected for branching coral and sand/rubble.

Habitat use in fish seemed to broadly match the habitat availability for most habitat categories in the study, with considerable differences in habitat availability among depths (Fig. 6b). The shallow habitat had a higher percentage cover of branching coral, plating coral, massive coral and algae/dead coral. Deeper habitat was characterised by having a higher percentage cover of soft coral, sand/rubble and other habitat categories. Overall, however, branching coral was used more than expected on the basis of availability. Branching corals have greater surface areas compared to other growth forms of coral, and this could have an effect on these results.

\section{DISCUSSION}

This study confirmed that reef fishes on the Great Barrier Reef exhibit strong patterns in distribution and community structure over depth gradients from 0 
to $20 \mathrm{~m}$. Some of these patterns conformed with predictions arising from previous studies (Green 1996, Eagle et al. 2001, Bean et al. 2002, Lecchini et al. 2003, Arias-González et al. 2006), while other observed patterns were unexpected. There were a large number of pomacentrid and labrid species primarily associated with shallow habitats, as well as numerous species with broader depth distributions and greater abundance in deeper habitats. Species diversity and taxonomic distinctness declined with depth. Other patterns were more complex than expected. The depth ranges of species increased with depth in shallow habitats (as expected), but ranges declined again in deeper habitats, with deeper species also tending to be specialists associated with the bottom edge of the reef at approximately $20 \mathrm{~m}$. Contrary to predictions, deeper habitat species tended to have narrower niches in terms of microhabitat use and were more reliant on branching corals than shallower species.

\section{Distribution and abundance}

There were clear patterns in the distribution and abundance with depth for both pomacentrids and labrids, with representative species from each family exhibiting similar patterns. Several species that were very common at shallow depths did not occur at greater depths (e.g. the pomacentrids Stegastes apicalis and Pomacentrus bankanensis and the labrids Thalassoma hardwicke and Thalassoma amblycephalus). There were also species that had broader depth distributions and were more common at greater depths (e.g. Pomacentrus brachialis and Thalassoma lunare). These results confirm previous observations that most reef fishes exhibit changes in abundance over relatively narrow depth ranges, and species-specific depth prefer-
Table 3. Species list containing all species of pomacentrids and labrids observed during the study and their feeding guilds. The number for each species corresponds to the data points in Fig. 5

\begin{tabular}{|c|c|c|c|}
\hline No. & Species & Family & Feeding guild \\
\hline 1 & Abudefduf sexfasciatus & Pomacentridae & Omnivore \\
\hline 2 & Abudefduf vaigiensis & Pomacentridae & Omnivore \\
\hline 3 & Abudefduf whitleyi & Pomacentridae & Omnivore \\
\hline 4 & Acanthochromis polyacanthus & Pomacentridae & Planktivore \\
\hline 5 & Amblyglyphidodon curacao & Pomacentridae & Omnivore \\
\hline 6 & Amblyglyphidodon leucogaster & Pomacentridae & Omnivore \\
\hline 7 & Amphiprion akindynos & Pomacentridae & Planktivore \\
\hline 8 & Anampses geographicus & Labridae & Benthic invertivore \\
\hline 9 & Anampses neoguinaicus & Labridae & Benthic invertivore \\
\hline 10 & Bodianus axilaris & Labridae & Benthic invertivore \\
\hline 11 & Cheilinus fasciatus & Labridae & Benthic invertivore \\
\hline 12 & Cheilinus trilobatus & Labridae & Benthic invertivore \\
\hline 13 & Choerodon fasciatus & Labridae & Invertivore \\
\hline 14 & Chromis atripectoralis & Pomacentridae & Planktivore \\
\hline 15 & Chromis lepidolepis & Pomacentridae & Planktivore \\
\hline 16 & Chromis margaretifer & Pomacentridae & Planktivore \\
\hline 17 & Chromis ternatensis & Pomacentridae & Planktivore \\
\hline 18 & Chrysiptera brownriggi & Pomacentridae & Omnivore \\
\hline 19 & Chrysiptera flavipinnis & Pomacentridae & Omnivore \\
\hline 20 & Chrysiptera glauca & Pomacentridae & Herbivore \\
\hline 21 & Chrysiptera rollandi & Pomacentridae & Planktivore \\
\hline 22 & Chrysiptera talboti & Pomacentridae & Planktivore \\
\hline 23 & Coris batuensis & Labridae & Benthic invertivore \\
\hline 24 & Dascyllus melanurus & Pomacentridae & Planktivore \\
\hline 25 & Dascyllus reticulatus & Pomacentridae & Planktivore \\
\hline 26 & Dischistodus melanotus & Pomacentridae & Territorial herbivore \\
\hline 27 & Dischistodus perspicillatus & Pomacentridae & Territorial herbivore \\
\hline 28 & Dischistodus prospotaenia & Pomacentridae & Territorial herbivore \\
\hline 29 & Epibulus insidiator & Labridae & Invertivore \\
\hline 30 & Gomphosus varius & Labridae & Benthic invertivore \\
\hline 31 & Halichoeres hortulanus & Labridae & Invertivore \\
\hline 32 & Halichoeres margaritaceous & Labridae & Benthic invertivore \\
\hline 33 & Halichoeres marginatus & Labridae & Invertivore \\
\hline 34 & Halichoeres melanurus & Labridae & Invertivore \\
\hline 35 & Halichoeres nigrescens & Labridae & Benthic invertivore \\
\hline 36 & Halichoeres prosopeion & Labridae & Benthic invertivore \\
\hline 37 & Hemigymnus fasciatus & Labridae & Invertivore \\
\hline 38 & Hemigymnus melapterus & Labridae & Invertivore \\
\hline 39 & Labrichthys unilineatus & Labridae & Coralivore \\
\hline 40 & Labroides dimidiatus & Labridae & Invertivore \\
\hline 41 & Labropsis australis & Labridae & Coralivore \\
\hline 42 & Neoglyphidodon melas & Pomacentridae & Omnivore \\
\hline 43 & Neoglyphidodon nigroris & Pomacentridae & Omnivore \\
\hline 44 & Neopomacentrus azysron & Pomacentridae & Planktivore \\
\hline 45 & Oxycheilinus diagramma & Labridae & Invertivore \\
\hline 46 & Plectroglyphidodon dickii & Pomacentridae & Omnivore \\
\hline 47 & Plectroglyphidodon lacrymatrus & s Pomacentridae & Territorial herbivore \\
\hline 48 & Plectroglyphidodon leucozonus & Pomacentridae & Territorial herbivore \\
\hline 49 & Pomacentrus amboinensis & Pomacentridae & Omnivore \\
\hline 50 & Pomacentrus bankanensis & Pomacentridae & Omnivore \\
\hline 51 & Pomacentrus brachialis & Pomacentridae & Omnivore \\
\hline 52 & Pomacentrus chrysurus & Pomacentridae & Herbivore \\
\hline 53 & Pomacentrus coelestis & Pomacentridae & Planktivore \\
\hline 54 & Pomacentrus mollucensis & Pomacentridae & Planktivore \\
\hline 55 & Pomacentrus nagasakiensis & Pomacentridae & Planktivore \\
\hline 56 & Pomacentrus philippinus & Pomacentridae & Planktivore \\
\hline 57 & Pseudocheilinus hexataenia & Labridae & Invertivore \\
\hline
\end{tabular}


Table 3 (continued)

\begin{tabular}{|llll|}
\hline No. & \multicolumn{1}{c}{ Species } & Family & Feeding guild \\
\hline 58 & Stegastes apicalis & Pomacentridae & Territorial herbivore \\
59 & Stegastes fasciolatus & Pomacentridae & Territorial herbivore \\
60 & Stegastes nigricans & Pomacentridae & Territorial herbivore \\
61 & Stethojulis bandanensis & Labridae & Benthic invertivore \\
62 & Thalassoma amblycephalum & Labridae & Planktivore \\
63 & Thalassoma hardwicke & Labridae & Invertivore \\
64 & Thalassoma jansenii & Labridae & Invertivore \\
65 & Thalassoma lunare & Labridae & Benthic invertivore \\
66 & Thalassoma lutescens & Labridae & Benthic invertivore \\
67 & Thalassoma quinquevittatum & Labridae & Benthic invertivore \\
\hline
\end{tabular}
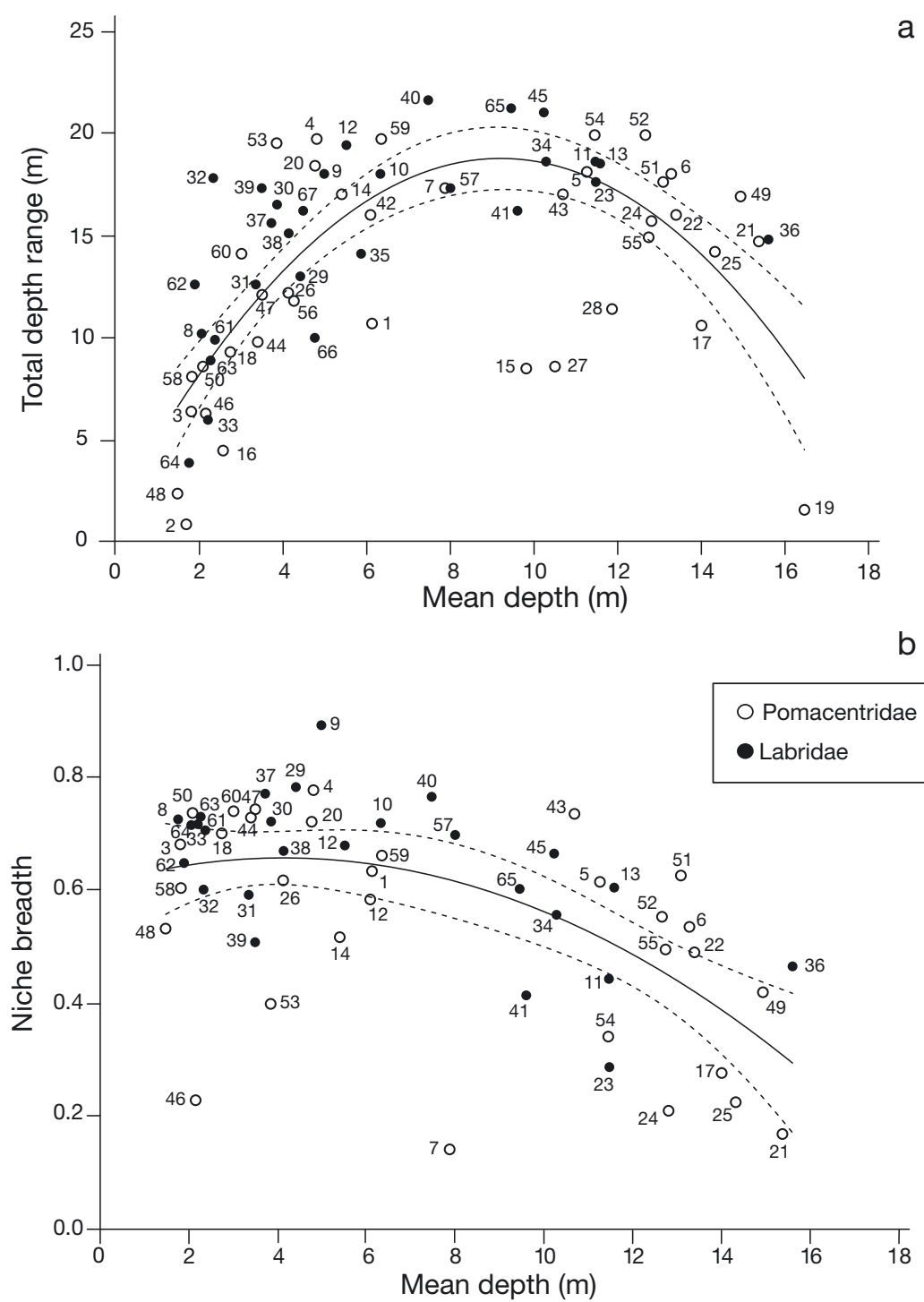

Fig. 5. (a) Total depth range and (b) niche breadth against the mean depth of occurrence for each species observed in the study. Total depth range is defined as the size of a species depth range in metres. Niche breadth is a measure of specialisation which gives a number between 0 and 1 for each species, where 0 is highly specialised and 1 is highly generalised. Numbers next to data points correspond to species numbers found in the species list (Table 3) ences (Bay et al. 2001, Bean et al. 2002, Donaldson 2002, HernandezLanda et al. 2015). The community level analyses showed the greatest difference in species composition, in the nMDS plot, occurred between the shallowest depth stratum (0-5 m) and the deeper reef areas. However, a continuous change in community structure occurred along the depth gradient to $20 \mathrm{~m}$, and these depth patterns were consistent among reefs. It confirms previous findings that depth can be one of the major factors explaining variation in fish distributions and community structure (Green 1996, Lecchini et al. 2003, Brokovich et al. 2008).

\section{Taxonomic diversity and distinctness}

Taxonomic diversity and distinctness decreased linearly with depth along the depth gradient, contrasting with previous studies, such as that by Brokovich et al. (2008), in which species diversity and richness increased with depth to the midpoint of the depth gradient before declining rapidly with increasing depth. Unlike the Brokovich et al. (2008) study, our study was limited to $20 \mathrm{~m}$ and used different measures of diversity, but encompassed the entire depth range available to reef fishes on the mid-shelf reefs surveyed. The presence of dominant habitat-dependent damselfish, such as Dascyllus reticulatus, on the deeper parts of the gradient may also reduce the abundance of other species, thereby reducing diversity. Ben-Tzvi et al. (2009) found that adults of a similar species of damselfish (Dascyllus aruanus) were very aggressive to settlers of both conspecifics and heterospecifics to their coral habitats and that this could influence the settlement preferences of juveniles. 

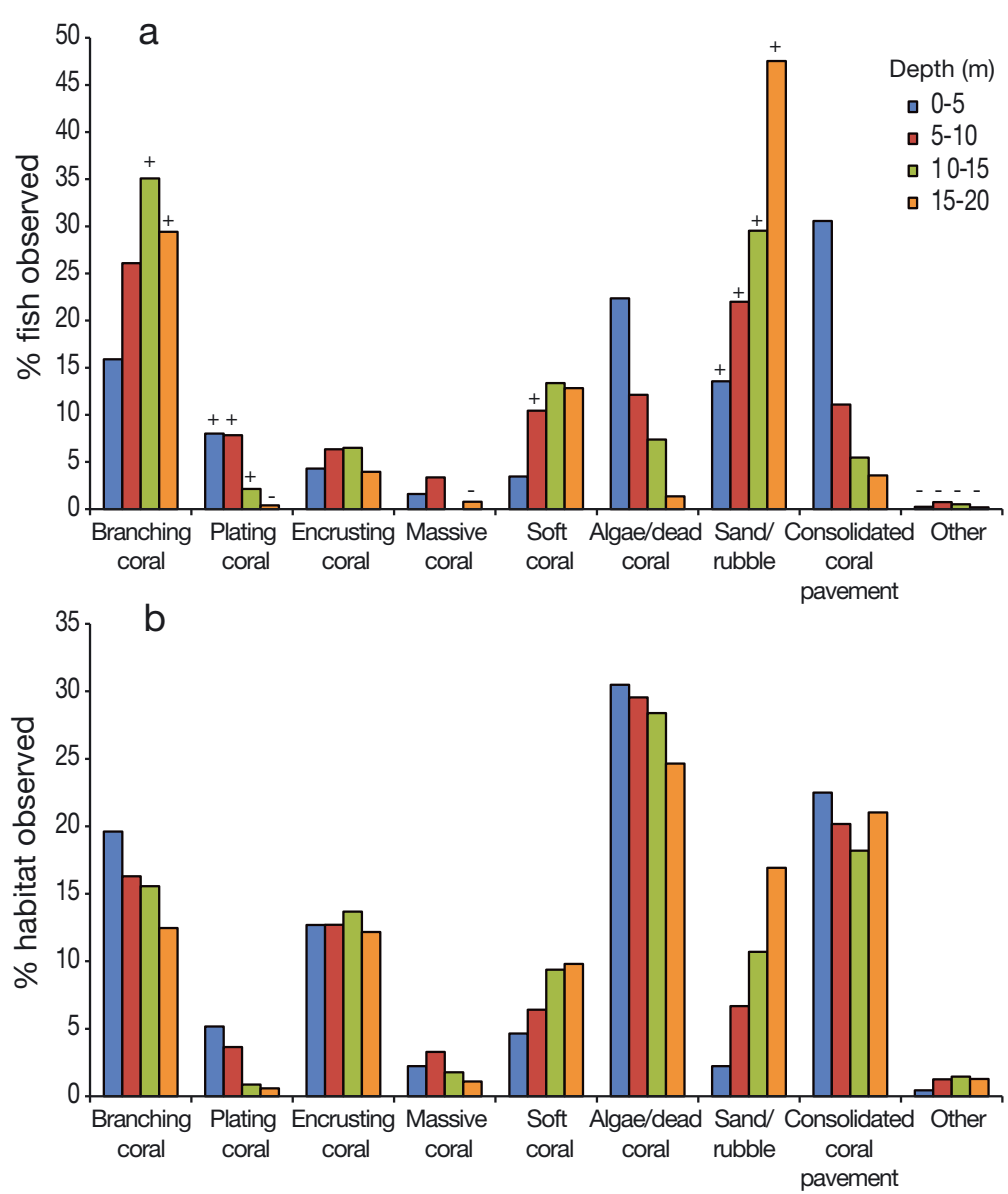

Fig. 6. (a) Percentage of fish observed using each of 9 habitat categories and (b) percentage of habitat for each of 9 habitat categories observed at shallow and deep depths along the gradient surveyed in the study. Data were categorised into 4 depth strata $(0-5,5-10,10-15$ and $15-20 \mathrm{~m})$. A resource function was calculated for fish data to show which habitats were preferred (+) and which were avoided (-); bars without symbols represent habitats that were not significantly preferred or avoided

\section{Depth ranges and niche breadth}

There were a number of unexpected patterns in terms of depth range and niche breadth along the depth gradient. The idea that shallow species are more specialised in terms of their depth and habitat use than deeper species (Bean et al. 2002) was only partially supported. Firstly, we found depth specialists in both shallow habitats and in habitats along the deepest parts of the depth gradient. Species with the broadest depth ranges were those recorded at intermediate depths. Secondly, specialisation in terms of substratum use increased with depth, whilst diversity decreased, in contrast to the results found in previous studies (Friedlander \& Parrish 1998, Bean et al. 2002, Brokovich et al. 2008). The dominance of particular species in the community at the deepest parts of the depth gradient may be causing the nonlinear relationship seen between depth and total depth range. A number of the species dominant at the bottom of the gradient are species that are primarily associated with small patch reefs on sand (e.g. D. reticulatus) or sandy habitats immediately adjacent to reefs (e.g. Chrysiptera rollandi).

This gradient, with potential boundaries and a pattern showing the highest depth ranges at the mid-point of the gradient, could be the result of a 'mid-domain effect'. The concept of a mid-domain effect is that a random distribution of geographic ranges produces a peak in species richness midway between the boundaries of a biogeographic domain (Connolly et al. 2003). Despite these patterns usually being described on much larger scales and the fact that many reefs extend much deeper than $20 \mathrm{~m}$, it is still possible to consider a mid-domain effect in our study because the reefs surveyed did not extend deeper than $20 \mathrm{~m}$, meaning we surveyed the entire depth range available to the fish communities on these reefs. To examine if there truly is a mid-domain effect with depth, further study on more continuous reefs, in terms of habitat, to much deeper depths would be required.

Niche breadth showed an unexpected negative relationship with mean depth of occurrence, suggesting that for the fish surveyed in this study, specialisation increased with depth, while diversity declined. This pattern was associated with mobile, less habitat-dependent species being common at shallow depths, such as Abudefduf whitleyi and Anampses geographicus, whilst more habitat-dependent and less mobile species were common at greater depths, such as D. reticulatus and C. rollandi. Predation pressure can increase with depth due to increased abundances of piscivores, which may lead to a closer association between small fishes and substrata that provide significant shelter at the deepest parts of the depth gradient (Shulman 1985, Jordan et al. 2012).

\section{Reliance on coral}

There was not a decline in the reliance on branching corals with increasing depth, as predicted. When looking at coral use for all species combined in the 
habitat use analysis, there was a much higher percentage of deeper fish using branching coral compared with shallower fish, despite only a small difference in the availability of branching coral between deeper and shallower habitats. At shallower depths, habitats such as algae/dead coral, consolidated coral pavement, sand/rubble and branching and plating corals were the most common habitats used by fish. In contrast the habitat usage at deeper depths was dominated by fewer habitats, which were branching coral and sand/rubble. It is thought that habitat specialists can have an advantage over generalists within a subset of resources, but are more likely to be affected by habitat availability, and that generalists are favoured in more heterogeneous and disturbed environments, whilst specialists occur in more stable environments (Wilson et al. 2008, Clavel et al. 2011). At the deepest parts of the depth gradient there were patches of unconnected branching corals; hence, coral-associated species were common and had depth ranges restricted to their patchy habitat.

Brokovich et al. (2008) suggested that a decrease in branching coral, seen with increases in depth, could help explain the change in dominance between families of reef fish that were more dependent on coral as shelter, such as damselfish at shallower depths compared to those which were generally less dependent on corals for shelter such as species of labrids. Our study found that branching coral habitat was still common at the deepest parts of the reef, allowing more habitat-specialised damselfishes (e.g. D. reticulatus) to dominate at depth. It should be noted that Brokovich et al. (2008) surveyed a much greater depth gradient $(0-65 \mathrm{~m})$ than we did in our study. Specialists may be able to use their preferred habitat more efficiently than generalists, meaning they could out-compete generalists in that habitat, leading to a dominance of specialists and a potentially less diverse community (Emlen \& Oring 1977, Futuyma \& Moreno 1988). Alternatively, specialisation can increase diversity by allowing ecologically similar species to coexist in the same environments through the partitioning of resources (Hutchinson 1959, Pereira et al. 2015).

Habitat use was similar to habitat availability, with higher complexity corals (branching and plating) being particularly important for reef fish (Graham \& Nash 2013, Coker et al. 2014). The underlying reef habitat and its characteristics are key factors in the distribution and abundance patterns of coral reef fishes (Graham \& Nash 2013). However, it has been shown that if habitat is controlled experimentally then depth patterns can still occur independent of habitat, suggesting that other physical factors that co- vary with depth may play a role in depth distribution patterns (Srinivasan 2003). Numerous physical and biological factors change with depth, including light attenuation (Brokovich et al. 2008, Irisson et al. 2010), water movement (Fulton \& Bellwood 2005, Fulton et al. 2005), larval supply (Leis 1986, 1991, Gutierrez 1998, Hendriks et al. 2001) and competition (Bay et al. 2001, Bean et al. 2002). In the same study, growth and survival were reduced when species with a particular depth preference were forced to live outside of their preferred depth range, showing that a cost to fitness is potentially involved (Srinivasan 2003).

\section{Depth: Is it a refuge?}

For the reefs surveyed, deeper species were more specialised and they may well be just as vulnerable to coral loss as shallower species. This could also suggest that on these shallow reefs depth may not provide much of a refuge, although, this would depend on the extent to which deeper habitat is impacted by a particular disturbance. This is similar to other studies which have found depth refuges on some reefs and not on others. For example, van Oppen et al. (2011) found evidence of vertical migration in populations of corals at a reef in north western Australia, but not on a reef in north eastern Australia. The fact that the reefs studied in this survey only reached depths of around $20 \mathrm{~m}$ is probably a limitation to a depth refuge. There is some evidence that impacts to corals from disturbances such as tropical cyclones and thermal bleaching can be reduced at depths $>10 \mathrm{~m}$, but the full depth of the reefs surveyed $(20 \mathrm{~m})$ may not be deep enough for the deeper reef habitat to act as a refuge (Woodley et al. 1981, Hoeksema 1991, Bak et al. 2005, Slattery et al. 2011, Bridge et al. 2013). Most of the literature discussing depth refuge involves mesophotic reefs which occur at depths between 30 and $60 \mathrm{~m}$ (Bak et al. 2005, Slattery et al. 2011, Bridge et al. 2013). Depth refuge has been shown to occur for coral reef fishes in relation to fishing and marine reserves (Tyler et al. 2009, Goetze et al. 2011). However, there are few studies that have looked into the possibility of depth providing a refuge for coral reef fishes in relation to other impacts. Graham et al. (2011) suggest that depth could be an important factor in the extinction risk of fish species, as those species that have extended depth ranges could in fact be less impacted by disturbances to shallower reef habitats.

This study has revealed a number of trends in the structure of reef fish communities along a depth gra- 
dient from 0 to $20 \mathrm{~m}$. These patterns include declining taxonomic diversity with depth, small depth ranges for both shallow and deeper water species, and increasing habitat specialisation and reliance on branching corals in deeper reef habitats. These patterns are likely explained by a range of factors, given the sharp gradients in the physical and biological environment between 0 and $20 \mathrm{~m}$ and also the presence of specialised species at deeper reef habitats. However, deeper reef habitats may be a refuge for coralassociated species, as long as these deeper corals have some resilience from bleaching or other depthrestricted disturbances. Our results highlight the need for further study into the causes of depth patterns and the long-term stability and resilience of coral-associated reef fish populations on deeper reef habitats.

Acknowledgements. We acknowledge the 'Kalinda' and her crew for their support on 2 great field trips. Thanks to our volunteers E. Bogaerts and T. Mannering for their aid in collecting the data and to K. Chong-Seng, K. Nash and F. Januchowski-Hartley for their support and humour in the field, making some rough weather much more bearable. Thank you also to C. Mattone for some help with the statistics and analysis. We also thank James Cook University for providing APA funding, as well as the Australian Research Council, the Centre of Excellence for Coral Reef Studies and Queensland Smart Futures Fund for helping to fund the field trips. This research was carried out under the approval of the James Cook University Animal Ethics Committee.

\section{LITERATURE CITED}

Arias-González JE, Done TJ, Page CA, Cheal AJ, Kininmonth S, Garza-Pérez JR (2006) Towards a reefscape ecology: relating biomass and trophic structure of fish assemblages to habitat at Davies Reef, Australia. Mar Ecol Prog Ser 320:29-41

Bak RPM, Nieuwland G, Meesters EH (2005) Coral reef crisis in deep and shallow reefs: 30 years of constancy and change in reefs of Curacao and Bonaire. Coral Reefs 24: 475-479

Bay LK, Jones GP, McCormick MI (2001) Habitat selection and aggression as determinants of spatial segregation among damselfish on a coral reef. Coral Reefs 20: 289-298

> Bean K, Jones GP, Caley MJ (2002) Relationships among distribution, abundance and microhabitat specialisation in a guild of coral reef triggerfish (Family Balistidae). Mar Ecol Prog Ser 233:263-272

> Bell JD, Galzin R (1984) Influence of live coral cover on coral reef fish communities. Mar Ecol Prog Ser 15:265-274

Ben-Tzvi O, Kiflawi M, Polak O, Abelson A (2009) The effect of adult aggression on habitat selection by settlers of two coral dwelling damselfishes. PLoS ONE 4:e5511

Bongaerts P, Ridgway T, Sampayo EM, Hoegh-Guldberg O (2010) Assessing the 'deep reef refugia' hypothesis: focus on Caribbean reefs. Coral Reefs 29:309-327

Bonin MC, Almany GR, Jones GP (2011) Contrasting effects of habitat loss and fragmentation on coral-associated reef fishes. Ecology 92:1503-1512

Bridge TCL, Hughes TP, Guinotte JM, Bongaerts P (2013) Call to protect all coral reefs. Nat Clim Change 3: 528-530

Brokovich E, Baranes A, Goren M (2006) Habitat structure determines coral reef fish assemblages at the northern tip of the Red Sea. Ecol Indic 6:494-507

Brokovich E, Einbinder S, Shashar N, Kiflawi M, Kark S (2008) Descending to the twilight-zone: changes in coral reef fish assemblages along a depth gradient down to 65 m. Mar Ecol Prog Ser 371:253-262

Chabanet P, Ralambondrainy H, Amanieu M, Faure G, Galzin R (1997) Relationships between coral reef substrata and fish. Coral Reefs 16:93-102

Clarke RM, Warwick KR (1998) A taxonomic distinctness index and its statistical properties. J Appl Ecol 35: 523-531

Clavel J, Julliard R, Devictor V (2011) Worldwide decline of specialist species: toward a global functional homogenization? Front Ecol Environ 9:222-228

> Coker DJ, Wlson SK, Pratchett MS (2014) Importance of live coral habitat for coral reef fishes. Rev Fish Biol Fish 24: 89-126

> Connell JH (1961) The influence of interspecific competition and other factors on the distribution of the barnacle Chthamalus stellatus. Ecology 42:710-723

> Connolly SR, Bellwood DR, Hughes TP (2003) Indo-Pacific biodiversity of coral reefs: deviations from a mid-domain model. Ecology 84:2178-2190

> Donaldson TJ (2002) Habitat association and depth distribution of two sympatric groupers of the genus Cephalopholis (Serranidae: Epinephelinae). Ichthyol Res 49:191-193

Eagle JV, Jones GP, McCormick MI (2001) A multi-scale study of the relationships between habitat use and the distribution and abundance patterns of three coral reef angelfishes (Pomacanthidae). Mar Ecol Prog Ser 214: 253-265

Emlen ST, Oring LW (1977) Ecology, sexual selection and the evolution of mating systems. Science 197:215-223

Friedlander AM, Parrish JD (1998) Habitat characteristics affecting fish assemblages on a Hawaiian coral reef. J Exp Mar Biol Ecol 224:1-30

Fulton CJ, Bellwood DR (2005) Wave-induced water motion and the functional implications for coral reef fish assemblages. Limnol Oceanogr 50:255-264

Fulton CJ, Bellwood DR, Wainwright PC (2005) Wave energy and swimming performance shape coral reef fish assemblages. Proc R Soc Lond B 272:827-832

Futuyma DJ, Moreno G (1988) The evolution of ecological specialisation. Annu Rev Ecol Syst 19:207-233

> Garpe KC, Yahya SAS, Lindahl U, Ohman MC (2006) Longterm effects of the 1998 coral bleaching event on reef fish assemblages. Mar Ecol Prog Ser 315:237-247

> Goetze JS, Langlois TJ, Egli DP, Harvey ES (2011) Evidence of artisanal fishing impacts and depth refuge in assemblages of Fijian reef fish. Coral Reefs 30:507-517

> González-Sanson G, Aguilar C, Hernandez I, Cabrera Y (2009) Effects of depth and bottom communities on the distribution of highly territorial reef fish in the northwestern region of Cuba. J Appl Ichthyol 25:652-660

Graham NAJ, Nash KI (2013) The importance of structural complexity in coral reef ecosytems. Coral Reefs 32: 315-326

Graham NAJ, Wilson SK, Jennings S, Polunin NVC, Bijoux 
JP, Robinson J (2006) Dynamic fragility of oceanic coral reef ecosystems. Proc Natl Acad Sci USA 103:8425-8429

Graham NAJ, Chabanet P, Evans RD, Jennings S and others (2011) Extinction vulnerability of coral reef fishes. Ecol Lett 14:341-348

Graham NAJ, Chong-Seng KM, Huchery C, JanuchowskiHartley FA, Nash KL (2014) Coral reef community composition in the context of disturbance history on the Great Barrier Reef, Australia. PLoS ONE 9:e101204

> Gratwicke B, Speight MR (2005) Effects of habitat complexity on Caribbean marine fish assemblages. Mar Ecol Prog Ser 292:301-310

> Green AL (1996) Spatial, temporal and ontogenetic patterns of habitat use by coral reef fishes (family Labridae). Mar Ecol Prog Ser 133:1-11

Gutierrez L (1998) Habitat selection by recruits establishes local patterns of adult distribution in two species of damselfishes: Stegastes dorsopunicans and S. planifrons. Oecologia 115:268-277

> Hawkins AFA (1999) Altitudinal and latitudinal distribution of east Malagasy forest bird communities. J Biogeogr 26: 447-458

- Hendriks IE, Wilson DT, Meekan MG (2001) Vertical distributions of late stage larval fishes in the nearshore waters of the San Blas Archipelago, Caribbean Panama. Coral Reefs 20:77-84

Hernandez-Landa RC, Acosta-González G, Nunez-Lara E, Arias González JE (2015) Spatial distribution of surgeonfish and parrotfish in the north sector of the Mesoamerican Barrier Reef System. Mar Ecol 36:432-446

> Hoeksema BW (1991) Control of bleaching in mushroom coral populations (Scleractinia: Funglidae) in the Java Sea: stress tolerance and interference by life history strategy. Mar Ecol Prog Ser 74:225-237

> Hutchinson GE (1959) Homage to Santa Rosalia or why are there so many kinds of animals? Am Nat 93:145-159

> Irisson JO, Paris CB, Guigand C, Planes S (2010) Vertical distribution and ontogenetic 'migration' in coral reef fish larvae. Limnol Oceanogr 55:909-919

Jankowski MW, Gardiner NR, Jones GP (2015) Depth and reef profile: effects on the distribution and abundance of coral reef fishes. Environ Biol Fishes 98:1373-1386

> Jordan LKB, Lindeman KC, Spieler RE (2012) Depth-variable settlement patterns and predation influence on newly settled reef fishes (Haemulon spp., Haemulidae). PLoS ONE 7:e50897

Kahng SE, Garcia-Sais JR, Spalding HL, Brokovich E and others (2010) Community ecology of mesophotic coral reef ecosystems. Coral Reefs 29:255-275

Kappelle M, Vanuffelen JG, Cleef AM (1995) Altitudinal zonation of montane Quercus forests along two transects in Chirripo National Park, Costa Rica. Vegetatio 119: 119-153

Krebs CJ (2006) Ecology after 100 years: progress and pseudo-progress. N Z J Ecol 30:3-11

> La Peyre MKG, Grace JB, Hahn E, Mendelssohn IA (2001) The importance of competition in regulating plant species abundance along a salinity gradient. Ecology 82: 62-69

> Lecchini D, Adjeroud M, Pratchett MS, Cadoret L, Galzin R (2003) Spatial structure of coral reef fish communities in the Ryukyu Islands, southern Japan. Oceanol Acta 26: $537-547$

Leingärtner A, Krauss J, Steffan-Dewenter I (2014) Species richness and trait composition of butterfly assemblages change along an altitudinal gradient. Oecologia 175: 613-623

Leis JM (1986) Vertical and horizontal distribution of fish larvae near coral reefs at Lizard Island, Great Barrier Reef. Mar Biol 90:505-516

Leis JM (1991) Vertical distribution of fish larvae in the Great Barrier Reef lagoon, Australia. Mar Biol 109: 157-166

Manly BFJ, McDonald LL, Thomas DL (1993) Resource selection by animals. Chapman and Hall, London

Mark AF, Dickinson KJM, Allen J, Smith R, West CJ (2001) Vegetation patterns, plant distribution and life forms across the alpine zone in southern Tierra del Fuego, Argentina. Austral Ecol 26:423-440

> McGehee MA (1994) Correspondence between assemblages of coral reef fishes and gradients of water motion, depth and substrate size off Puerto Rico. Mar Ecol Prog Ser 105:243-255

> Nogués-Bravo D, Araujo MB, Romdal T, Rahbek C (2008) Scale effects and human impact on the elevational species richness gradients. Nature 453:216-219

Pereira PHC, Munday PL, Jones GP (in press) Competitive mechanisms changes with ontogeny in coral-dwelling gobies. Ecology 96:3090-3101

R Core Team (2014) R: a language and environment for statistical computing. R Foundation for Statistical Computing, Vienna, www.r-project.org

> Shulman MJ (1985) Recruitment of coral reef fishes: effects of distribution of predators and shelter. Ecology 66: 1056-1066

Silc U, Lososova Z, Vrbnicanin S (2014) Weeds shift from generalist to specialist: narrowing of ecological niches along a north-south gradient. Preslia 86:35-46

Slattery M, Lesser MP, Brazeau D, Stokes MD, Leichter JJ (2011) Connectivity and stability of mesophotic coral reefs. J Exp Mar Biol Ecol 408:32-41

Srinivasan M (2003) Depth distributions of coral reef fishes: the influence of microhabitat structure, settlement, and post-settlement processes. Oecologia 137:76-84

Tyler EHM, Speight MR, Henderson P, Manica A (2009) Evidence for a depth refuge effect in artisanal coral reef fisheries. Biol Conserv 142:652-667

> van Oppen MJH, Bongaerts P, Underwood JN, Peplow LM, Cooper TF (2011) The role of deep reefs in shallow reef recovery: an assessment of vertical connectivity in a brooding coral from west and east Australia. Mol Ecol 20: 1647-1660

> Warwick RM, Clarke KR (1995) New 'biodiversity' measures reveal a decrease in taxonomic distinctness with increasing stress. Mar Ecol Prog Ser 129:301-305

Wilson SK, Graham NAJ, Pratchett MS, Jones GP, Polunin NVC (2006) Multiple disturbances and the global degradation of coral reefs: Are reef fishes at risk or resilient? Glob Change Biol 12:2220-2234

- Wilson SK, Burgess SC, Cheal AJ, Emslie M and others (2008) Habitat utilization by coral reef fish: implications for specialists vs. generalists in a changing environment. J Anim Ecol 77:220-228

> Woodley JD, Chornesky EA, Clifford PA, Jackson JBC and others (1981) Hurricane Allen's impact on Jamaican coral reefs. Science 214:749-755

> Xu Y, Chen YN, Li WH, Fu AH, Ma XD, Gui DW, Chen YP (2011) Distribution pattern of plant species diversity in the mountainous region of Ili River Valley, Xinjiang. Environ Monit Assess 177:681-694 